\title{
O MITO DA LIQUIDEZ
}

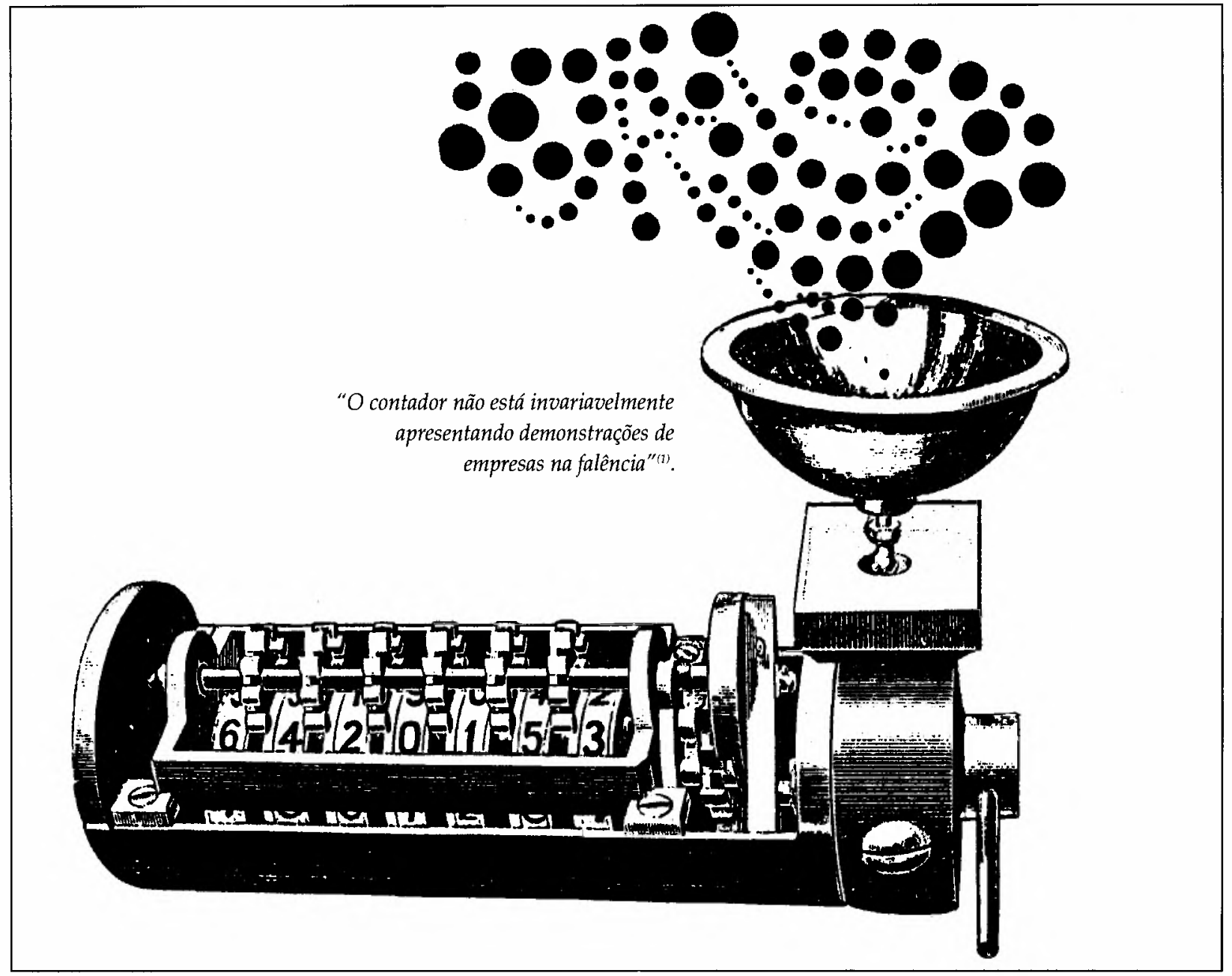

\section{JOÃo CARLOS HOPP}

Professor Titular no Departamento de Contabilidade, Finanças e Controle da EAESP/FGV.

\section{- HÉLIO DE PAULA LEITE}

Professor Assistente no Departamento de

Contabilidade, Finanças e Controle da EAESP/FGV.

RESUMO: A análise financeira tradicional pressupõe a liquidação da empresa no curto prazo e, arbitrariamente, classifica os chamados indices de liquidez em padrões pré-estabelecidos.

Embora esses índices sejam fáceis de calcular, é primordial que o usuário esteja ciente da condição estática da informação e que as dúvidas sejam resgatadas pelo fluxo de recursos produzidos pelas operações dos ativos e não pela sua liquidação.

Os indices financeiros têm sido supervalorizados como instrumento eficiente de previsão de falências de empresas, sendo que ultimamente o fluxo de caixa tem sido considerado como um melhor indicador de dificuldades financeiras das empresas.

PALAVRAS-CHAVE: Índice de endividamento, hipótese de continuidade, ativo circulante, passivo circulante, capital circulante líquido, fluxo de caixa.

1. PATON, William A. "Valuation of Investories".In: The Journal of Accountancy, dezembro, 1922. 


\section{INTRODUÇÃO}

A análise financeira tradicional parece estar inspirada pela hipótese pouco plausível de que a empresa em estudo vai ser liquidada no momento imediatamente seguinte ao do levantamento do balanço patrimonial. Ainda hoje, o confronto e relacionamento de cifras extraídas do lado esquerdo e do lado direito dos balanços conseguem empolgar os usuários das demonstrações contábeis e convencê-los de que o diagnóstico da saúde financeira dos empreendimentos é algo trivial: tudo de que precisamos é dominar o conceito da porcentagem.

Se a relação percentual entre o exigível total e o ativo total for igual a $50 \%$ ou maior do que estes, estamos diante de uma empresa endividada; se a relação entre ativos circulantes e passivos circulantes for inferior a dois, devemos começar a desconfiar de sua solvência; se for menor do que um, podemos ter certeza de que ela está em crise. Em todos esses raciocínios, está subjacente o pressuposto ingênuo de que o pagamento das dívidas da empresa depende da liquidação de seus ativos, algo que somente ocorre quando a empresa está efetivamente sendo fechada.

A análise do valor patrimonial das ações, por exemplo, é uma tentativa de se chegar ao seu "valor intrínseco" pela liquidação dos ativos possuídos pela empresa na data do balanço aos seus respectivos custos históricos (eventualmente corrigidos), simultaneamente à liquidação do estoque de dívidas reconhecidas nessa mesma data. $\mathrm{O}$ próprio índice de endividamento geral, parâmetro tão decisivo em muitas análises financeiras, tenta descobrir a "capacidade de pagamento das dívidas" que a empresa tem pela liquidação de seus ativos.

A popularidade dos índices financeiros decorre essencialmente de sua simplicidade conceitual e da mística de precisão e conservadorismo que cerca o balanço patrimonial. Para se alcançar um diagnóstico financeiro mais útil e consistente, é preferível afastar a hipótese predominante da liquidação da empresa, um ranço do conservadorismo extremado e um fruto da comodidade das supersimplificações. Apesar de ampliar a complexidade e os riscos da análise externa, a hipótese de continuidade das operações da empresa tem que ser restaurada no direcionamento dos julgamentos do analista, a não ser que, efetivamente, a empresa esteja para ser liquidada. Sob essa ótica mais realista, devemos enxergar a empresa dando continuidade às suas operações, recebendo de seus clientes e pagando seus credores. É essencial, nesse diagnóstico, que se con- siderem as limitações características da matériaprima do trabalho do analista - o balanço patrimonial - e o seu verdadeiro e singelo significado: um levantamento instantâneo dos estoques de direitos e obrigações, de origens e aplicações de recursos em determinada data. Antes de condenar uma empresa pelo alto endividamento ou pela baixa liquidez, precisamos de lembrar que suas dívidas atuais não serão saldadas pela realização de seus ativos aos seus respectivos custos mas, pelo fluxo de recursos produzidos por suas operações. Também é essencial que se afaste a idéia simples, mas enganadora, de que o balanço patrimonial deve refletir o valor da empresa. Mesmo que estivéssemos utilizando o valor de mercado (e não o custo) como base para avaliação dos ativos, o patrimônio líquido não seria uma aproximação válida do valor do empreendimento. A empresa vale pelo que sua operação pode produzir de rendas no futuro. Somente em caso de liquidação, o patrimônio líquido a preços de mercado teria alguma utilidade para o avaliador.

\section{O MITO E SEUS PRECONCEITOS}

O hábito é tão arraigado que ao lermos um balanço pela primeira vez procuramos mentalmente calcular, de início, a liquidez corrente da empresa e, a seguir, o seu endividamento. Há uma fixação irresistível quanto ao índice de liquidez e os leitores das demonstrações contábeis geralmente o supervalorizam. Mas, é preciso ter alguns cuidados ao se interpretar esse indicador. Em primeiro lugar, a consistência parece não ser o seu forte. Pedimos ao leitor que responda qual a conseqüência da contratação de um empréstimo bancário de curto prazo sobre o nível do índice de liquidez de uma empresa. Intuitivamente, diríamos que um novo financiamento de curto prazo diminuiria o índice de liquidez, mas tudo dependerá do valor do quociente entre ativo circulante e passivo circulante antes do empréstimo. Fazendo as contas, chegamos à desconcertante conclusão de que se o índice era inferior a unidade, o novo empréstimo de curto prazo aumentará a liquidez no momento seguinte ao do empréstimo pela expansão igual do numerador e do denominador. Simetricamente, o pagamento de uma dívida de curto prazo reduzirá o índice de liquidez corrente, caso ele seja menor do que um antes do pagamento. Ironicamente, para aumentar o índice de liquidez corrente de uma empresa com problemas de liquidez, deve-se ampliar ainda mais o seu passivo circulante!

Em segundo lugar, há o problema dos "padrões" de liquidez que inconscientemente temos gravados em nosso cérebro. Para liquidez cor- 
rente, o "ideal" é acima de dois; para a liquidez seca, aceita-se um; e para a liquidez imediata, quanto maior, melhor. Certamente, nada pode ser mais arbitrário do que julgar a situação de empresas pelos nossos inexplicáveis preconceitos. Uma cadeia de lojas de varejo em expansão, comprando a prazo e vendendo à vista, tenderá a apresentar índices medíocres de liquidez corrente; uma empresa na menopausa tenderá a apresentar elevados índices de liquidez imediata; uma empresa em fase de retração de negócios (vendendo mais do que compra) tenderá a apresentar índices crescentes de liquidez seca; uma empresa superestocada (inclusive com itens obsoletos) e abarrotada de duplicatas a receber em atraso, pode apresentar um invejável índice de liquidez corrente.

Em terceiro lugar, as limitações presentes ao significado do balanço patrimonial (estoques instantâneos de bens, direitos e obrigações) se transferem para todos os índices dele extraídos. A liquidez pode ser boa ou má através da análise de um determinado balanço, mas, como o próprio balanço, ela se refere ao momento do fechamento das contas o qual não é, necessariamente, o mais representativo da vida da empresa. Além disso, a liquidez da empresa pode ser aparentemente elevada, mas pode haver uma concentração imediata dos vencimentos de seus compromissos contra um prazo médio mais lento de realização de seus ativos circulantes. Tudo isso faz com que a convencional interpretação dos índices de liquidez corrente - quantos cruzados novos se dispõem de bens e direitos realizáveis a curto prazo para pagar cada cruzado novo de dívidas vencíveis a curto prazo - se torne extremamente vulnerável.

\section{UMA QUESTÃO DE CLASSIFICAÇÃO}

O tema da classificação de ativos e passivos em circulantes e não circulantes foi tratado com muita propriedade por Loyd C. Heath em seu clássico artigo "Is Working Capital Really Working?" Para ele, "o único atributo que todos os ativos classificados como circulantes têm em comum é que eles são ativos classificados como circulantes dentro das atuais práticas aceitas, um atributo que não possui conteúdo informacional algum para o usuário de demonstrativos financeiros preocupado com a avaliação da solvência da empresa; ... uma obrigação circulante só pode ser descrita como uma obrigação que é classificada como circulante ${ }^{\prime \prime(2)}$.

Entre os vários exemplos que Heath apresenta para reforçar o seu argumento, vale a pena citar a questão colocada por Phillip E. Fess quanto ao fato de uma apólice de seguro, válida por três anos e paga antecipadamente, ser classificada como ativo circulante, enquanto que uma máquina com três anos de vida útil prevista ser classificada

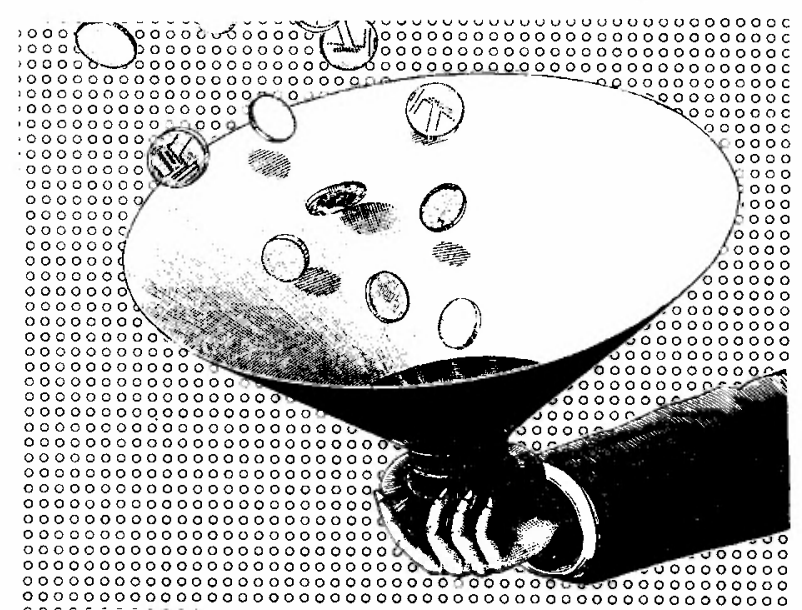

como imobilizado $^{(3)}$. A classificação de óleo cru estocado em tanques como ativo circulante $e$ reservas similares existentes no subsolo como ativo permanente parece não conter muita lógica.

$\mathrm{Na}$ verdade, o pressuposto básico da classificação circulante/não circulante é que os ativos circulantes serão realizados ao longo do próximo ciclo operacional da empresa, ou, ao longo do próximo exercício social. Nada impede, entretanto, de um ativo não circulante ser realizável no próximo exercício social. Aliás, a depreciação dos ativos permanentes é uma forma de realização desses investimentos através de parcelas dos recursos gerados pela operação da empresa. Por outro lado, a venda de um item do estoque (realização), usualmente, obriga a empresa a repô-lo no mesmo exercício social, o que significa que, de certa forma, esse investimento também é permanente (não circulante). J.Fred Weston \& Thomas E. Copeland referem-se a uma parte significativa do ativo circulante como "Ativo Circulante Permanente", para destacar um tipo de aplicação de recursos que tende a se ampliar quando o nível de operações da empresa está em expansão ${ }^{(4)}$. Mais uma vez, não é a realização total dos ativos circulantes que vai fornecer recursos para o pagamento das dividas de curto prazo. A operação da empresa é que gerará fluxos de recursos (conceito dinâmico, em oposição à estática do balanço patrimonial) para o pagamento dos seus compromissos.

2. HEATH, Loyd C. "Is Working Capital Really Working?"In: The Journal of Accountancy, agosto, 1980, p.57.

3. FESS, Phillip E. "The Working Capital Concept". In: The Accounting Review, abril, 1966, p.267, apud HEATH, Loyd C.Op.cit., p.56.

4. WESTON, J. Fred \& COPELAND, Thomas E. Managerial Finance. (8a. edição) New York, The Dryden Press, 1986,pp.281-283. 
Também a classificação do estoque das dívidas da empresa em circulante e não circulante, tomada de forma estrita, é falaciosa e não tem grande conteúdo informacional. Muito mais útil, para efeito de diagnóstico empresarial, como sugere Heath, seria a divisão das dívidas em financiamentos espontâneos e financiamentos contratados $^{(5)}$. Os financiamentos espontâneos são aqueles que nascem da própria operação desenvolvida pela empresa (fornecedores, impostos indiretos a recolher, imposto de renda a pagar, salários e outras contas a pagar que se originam do fato de estar a empresa operando), enquanto que financiamentos contratados são aqueles contraídos pela empresa junto a agentes financeiros e que resultam de um processo decisório financeiro. Do ponto de vista da empresa em operação, essa distinção é fundamental porque financiamentos espontâneos são recorrentes e, geralmente, não são onerosos. Um fabricante de bebidas ou cigarros, por exemplo, tenderá a acumular altos níveis de passivo circulante através do item "impostos indiretos a recolher"; quanto mais ele vende, mais ele deve. Segundo o "Balanço Anual" da Gazeta Mercantil de 1988, a mediana dos índices de liquidez corrente de 40 empresas do subsetor de refrigerantes e águas era de 1,00 (dessas 40 empresas, apenas 7 tinham índices superiores a 1,39). $O$ subsetor de cervejas e chopes apresentava a mediana de 1,03 (20 empresas) e o de cigarros e fumos, de 1,05 (8 empresas) ${ }^{(6)}$.

O balanço patrimonial consolidado do Grupo Souza Cruz em 31.12.88 revelava uma liquidez corrente de 1,51, aparentemente modesta quando julgada pelo velho padrão de liquidez corrente de 2:1. Tentando classificar as contas do Passivo Circulante, entretanto, estima-se que apenas 0,58\% das dívidas a curto prazo da empresa se referem a financiamentos contratados, enquanto que $48,24 \%$ desse grupo do passivo eram constituídos por IPI a recolher, outros Impostos a Recolher e Provisão para o Imposto de Renda. A participação dos Fornecedores e Contas a Pagar no passivo circulante era de $24,16 \%$, enquanto que $16,25 \%$ se referiam a dividendos a pagar (o restante do passivo circulante era constituído por Encargos Sociais a Recolher e outras provisões). A propósito, os financiamentos contratados com vencimento a curto prazo eram os únicos do passivo total e representavam $0,21 \%$ do ativo total. Como é possível torcer o nariz diante do índice de liquidez corrente de 1,51 ?

Quanto às dívidas contratadas, estamos diante de decisões de financiamento tomadas pelas empresas que representam fontes onerosas de recursos que não nascem espontaneamente da operação por elas desenvolvidas e cuja renovação depende de novas negociações, a custos eventualmente crescentes. Mesmo aqui, pouca informação útil pode ser obtida pela comparação das dívidas contratadas com os ativos realizáveis a curto prazo. Mais importante é a comparação do lucro operacional que a empresa obtém com os juros em que ela incorre (índice de cobertura das despesas financeiras), tanto em empréstimos de curto como os de longo prazos. No caso dos financiamentos contratados, é essencial conhecer em detalhe o perfil do endividamento total, importante informação que deveria vir obrigatoriamente no rodapé das demonstrações publicadas pelas empresas. Para facilitar a previsão do fluxo de caixa da empresa em análise, esse perfil poderia ser subdividido em períodos convenientemente curtos (como um trimestre ou um semestre), para que o analista pudesse localizar acumulações de vencimentos das amortizações. $\mathrm{O}$ custo médio de cada linha de crédito contratada também deveria ser informado no rodapé.

\section{PREVENDO A FALÊNCIA}

É surpreendente como se tenta enxergar através do balanço a possibilidade da falência, como se um demonstrativo essencialmente estático pudesse dispensar o incômodo e arriscado exercício da previsão. $\mathrm{Na}$ verdade, a estatística e informações extra-contábeis, mais do que relacionamentos de débitos e créditos, constituem instrumentos mais adequados para essa finalidade.

Inúmeras pesquisas foram realizadas para se determinar a capacidade dos índices financeiros em prever falências. Baruch Lev dedica inteiramente o capítulo 9("The Prediction of Corporate Failure") de seu livro Financial Statement Analysis: A New Approach ao levantamento e comentário desses estudos ${ }^{(t)}$. Em particular, a pesquisa realizada por William H. Beaver merece atenção especial $^{(8)}$.

5. HEATH cita Pearson Hunt, Charles M. Williams e Gordon Donaldson como proponentes dessa classificação - veja notas de rodapé números 18 e 19 do artigo de HEATH, Loyd C. Op. cit., p.59.

6. BALANÇO Anual. Gazeta Mercantil, outubro de 1988, p.156.

7. LEV, Baruch. Financial Statement Analysis: A New Approach. Englewood Cliffs, Prentice Hall, 1974, pp. 133-151.

8. BEAVER, William $\mathrm{H}$. "Alternative Accounting Measures as Predictors of Failure". In: Accounting Review, janeiro, 1968 pp. 113-122, apud LEV, Baruch. Op. cit, p. 141. 
Os resultados obtidos por Beaver indicam que o índice mais adequado para previsão de falências é a relação entre o fluxo de caixa (lucro líquido + depreciação) e o total da dívida. $O$ segundo melhor índice, segundo esse estudo, é a relação entre lucro líquido e ativo total. "Surpreendentemente, o indice de liquidez corrente estava entre os piores previsores (de falências)"(9). Por outro lado, relaçōes entre fluxos de caixa e estoques de dívidas parecem mais efetivos na avaliação da solvência.

Com efeito, a previsão de falências (um evento raro) e a previsão de dificuldades financeiras (um evento mais comum) são exercícios de antecipação de cenários operacionais críticos para a empresa, os quais somente podem ser esboçados a partir de um razoável conhecimento da operação que ela desenvolve e das condições do setor específico onde ela está estabelecida. Dados contábeis constituem apenas parte da base de informações sobre a qual apoiaremos nosso diagnóstico, nossas previsões e nossas decisões.

Com relação, especificamente, à contribuição de análise econômico-financeira tradicional ao exercício da previsão de falências ou de crises de liquidez, cremos que ela tem sido supervalorizada. Um detalhado exame da seqüência de demonstrativos de fluxo de caixa irá ilustrar melhor a iminência de uma deterioração financeira que é conseqüência e não causa do malogro econômico. Num contexto analítico mais amplo, mais dinâmico e menos sujeito a arbitrariedades contábeis, o centro do diagnóstico será a análise, através de uma série histórica suficientemente longa, das tendências que governam a evolução do fluxo de caixa gerado pelas operações. As dificuldades financeiras nascem da disritmia entre entradas e saídas de caixa que somente pode ser detectada pelo minucioso estudo de uma coleção de demonstrativos de fluxo de caixa recentes da empresa em análise. $\mathrm{O}$ ritmo das entradas de caixa provenientes das operações deve estar coerente com os desembolsos por elas provocado e com a cobertura do serviço da dívida. O ritmo dos investimentos permanentes novos deve estar coerente com a disponibilidade de fundos levantados junto a acionistas, credores de longo prazo, ou acumulados pelas próprias operações. $\mathrm{O}$ diagnóstico se resume, portanto, numa análise de tendências desses fluxos, de forma dinâmica, por um analista não apenas inteirado dos demonstrativos financeiros básicos da empresa, mas, sobretudo, bem informado sobre o negócio da empresa e situação do seu setor; jamais esse diagnóstico pode se limitar a uma divisão elementar de saldos devedores por saldos credores. O produto final do diagnóstico deve constituir-se de projeções dos fluxos de caixa da empresa em análise e, por isso mesmo, a análise da solvência torna-se mais complexa e mais arriscada do que a simples conferência se o índice de liquidez corrente supera ou não o nível de 2. Para realizar esse diagnóstico, é indispensável o domínio de técnicas de previsão.

\section{NEM SEMPRE MAIS É MELHOR}

A tradicional análise de liquidez nos legou um terrível cacoete que é partir inconscientemente do princípio de que, quanto maior for o índice, melhor a situação da empresa em análise, como se fosse esse um indicador da qualidade do empreendimento.

Nesta época de juros estratosféricos, o único agente econômico disposto a assumir empréstimos é o governo que, por ter o monopólio da emissão de moeda, não se intimida diante do absurdo do custo financeiro incorrido ao se tomar emprestado. As empresas, por outro lado, submetidas ao mandamento da lucratividade, passam a fugir do endividamento como o diabo da cruz. Suas disponibilidades são canalizadas para - Open Market, onde é possível ganhar um retorno satisfatório e, em princípio, livre de riscos. Em conseqüência, os índices de liquidez, especialmente os de liquidez imediata, começam a se elevar demasiadamente, não sendo incomum encontrar empresas não financeiras na praça com índices superiores a 0,40. Será que o fato de uma empresa manter no disponível $40 \%$ do valor de suas dívidas vencíveis em um ano é um sinal positivo? Não é isto uma evidênca clara de que suas operações estão rendendo menos que o Open Market e que ela já não consegue fazer pelo seu acionista mais do que ele pode fazer sozinho emprestando diretamente suas poupanças ao governo, sem a intermediação financeira da empresa (homemade leverage)?

Em matéria de crises da economia brasileira, o mais sensato que podemos dizer é que não se fabricam mais crises como antigamente... Com efeito, nas fases críticas anteriores às da década de 80 , altos endividamentos coincidiam com baixos índices de liquidez, retração da demanda $\mathrm{e}$ explosão das despesas financeiras. Atualmente, a nova crise brasileira é caracterizada pelo baixo endividamento $\mathrm{e}$ alta liquidez das empresas nacionais que, literalmente, estão encolhendo sob o nefasto efeito da postergação indefinida dos investimentos permanentes. $O$ nosso parque industrial está sendo precocemente sucateado

9. LEV, Baruch. Op. cit., p.142. 
porque, há muito, a velocidade da depreciação supera o ritmo dos investimentos, abrindo-se um perigoso hiato de reposição de máquinas, instalações, edifícios, veículos etc. Em comum, a nova e a antiga crise têm, apenas, a elevação do custo financeiro, paradoxalmente, fazendo coincidir recordes de despesas financeiras com os menores índices de endividamento de nossa história recente. Enquanto isso, o ativo total segue decrescendo em termos reais porque o imobilizado não está sendo reposto no mesmo ritmo em que está se depreciando. Nessas circunstâncias tão particulares, como julgar o firme crescimento dos índices de liquidez da empresa nacional que coincide com o seu virtual encolhimento?

Temos que reconhecer algum tipo de relacionamento inverso entre liquidez e evolução do imobilizado. Uma empresa industrial em início de operação, normalmente, tenderá a apresentar apertados índices de liquidez. Na medida em que o tempo for passando e a operação não gerar prejuízos, fundos relativos à depreciação migrarão do imobilizado para o ativo circulante e ali se acumularão à espera do momento apropriado para a renovação do imobilizado: tudo mais constante, a liquidez se eleva. Uma queda abrupta de liquidez no exercício onde a empresa renova seus imobilizados não deveria surpreender ou preocupar o analista externo.

Quando ocorre uma calmaria nos negócios, a renovação do imobilizado é postergada sine die, caindo a sua produtividade e comprometendo a atualização tecnológica da empresa. Se essa calmaria se alonga por anos seguidos, como na atual conjuntura brasileira, a elevação dos índices de liquidez não refletem necessariamente saúde financeira, mas, ao contrário, denunciam o nefasto processo de encolhimento empresarial das empresas que vão para o Open Market enquanto esperam melhores dias. Se essa espera consumir anos seguidos não haverá mais como reverter a tendência à extinção. $\mathrm{O}$ culto exagerado aos índices de liquidez dão aos empresários, executivos e analistas externos a falsa sensação de que "tudo está sob controle", quando, na verdade, o empreendimento se encontra seriamente ameaçado.

O conceito de Capital Circulante Líquido (Net Working Capital) é outro instrumento que herdamos da análise convencional de balanços cuja utilidade está sendo duramente questionada. Se esse conceito for descartado, a famosa Demonstração de Origens e Aplicações (hoje de publicação obrigatória) será também abandonada, aparecendo em seu lugar a Demonstração do Fluxo de Caixa. Com efeito, a única diferença essencial entre esses demonstrativos reside em se adotar ou não o conceito de Capital Circulante Líquido.

Vale a pena refletir sobre a utilidade real da informação trazida pela mensuração do Capital Circulante Líquido. Qual a utilidade de sabermos quantos cruzados novos de ativo circulante são financiados por fontes permanentes (patrimônio líquido + exigível a longo prazo)? Não estaríamos aqui fazendo a ingênua associação entre itens do ativo e do passivo tão comum aos alunos que pela primeira vez fecham um balanço? Não será uma supersimplificação grosseira tentarmos localizar, através de um único balanço, as fontes que financiam os ativos circulantes de uma empresa? Da mesma forma como não podemos dizer que "o patrimônio líquido financia o ativo permanente", não podemos fazer ligações entre pontos do passivo e do ativo circulante. Mais eficiente será considerarmos o passivo como uma mistura de financiamentos que deram origens a uma carteira de ativos. O que realmente interessa é a composição e o custo do mix de financiamento e a rentabilidade operacional da carteira de ativos. Além disso, há o problema da arbitrariedade e inconsistência da classificação circulante/não circulante.

O conceito do Capital Circulante Líquido (Ativo Circulante - Passivo Circulante) conduz o analista à posição simplista de saudar os aumentos de ativo circulante e condenar o aumento do passivo circulante. Nem todo o aumento de ativo circulante é desejável e nem todo aumento de passivo circulante é prejudicial à rentabilidade operacional e à saúde do fluxo de caixa do empreendimento. O caso do excesso de aplicações no Open Market e o caso dos financiamentos espontâneos de curto prazo ilustram bem essa constatação.

\section{CONCLUSÕES}

Não precisamos descartar totalmente todos os instrumentos analíticos que herdamos da tradicional escola de análise financeira. Basta que reconheçamos suas limitações e façamos a adequação de seu real significado, não tomando ao pé da letra definições do tipo "quantos cruzados novos dispõem de bens e direitos realizáveis a curto prazo para cobrir cada cruzado novo de dívidas a curto prazo". Tomando essas precauções, evitaremos definitivamente a adoção generalizada de padrões (como o de 2:1 para liquidez corrente e 50\% para endividamento geral). Isso posto, precisamos nos convencer de que a previsão de falências e de crises financeiras não depende exclusivamente do acompanhamento desses índices tradicionais. Esse é um exercício mais complexo que requer 
novos índices que relacionem adequadamente números retirados do balanço do demonstrativo de resultados e, principalmente, do demonstrativo do fluxo de caixa.

O analista externo cada vez mais deverá apoiar seu diagnóstico no estudo detalhado da demonstração do fluxo de caixa e em informações não contábeis, como as condições específicas do setor de atividade da empresa em análise e sua posição relativa frente à concorrência. É a flexibilidade financeira da empresa que precisa ser avaliada diante de cenários macroeconômicos e setoriais alternativos, entendendo-se por "flexibilidade financeira" a "capacidade da empresa em controlar seus recebimentos e pagamentos de forma a sobreviver em períodos de adversidade financeira" ${ }^{\prime \prime(10)}$.

Quanto à classificação de circulante/não circulante, cremos (como recomenda Heath em seu artigo) que ela deva ser abandonada dando lugar a uma nova classificação de maior conteúdo informacional (como, por exemplo, financiamentos espontâneos e contratados). De qualquer forma, entretanto, não se trata de abandonar a tradicional ordem de liquidez para a apresentação dos ativos e dos prazos de vencimento para a dos passivos. Como diz Heath, "ativos devem continuar a ser classificados na ordem convencional (de liquidez) porque alterá-la corresponderia a confundir os usuários da mesma forma que alterar a ordem das teclas de uma máquina de escrever confundiria o datilografo" $(11)$.

$\mathrm{O}$ artigo de Loyd C. Heath ${ }^{(12)}$ mereceu respostas de três eminentes autoridades em teoria contábil: Leopold A. Bernstein, Kenneth S. Most e Max Block. A defesa do conceito de Capital Circulante Líquido e dos índices de liquidez por esses três autores consagrados aparecem na edição de dezembro de 1981 do Journal of Accountancy juntamente com a resposta de Loyd $C$. Heath a essas críticas $^{(13)}$.

Resumindo essas críticas, pode-se dizer que o argumento mais forte em favor do conceito convencional de liquidez está na sua grande popularidade e na tradição que o cerca. Parece que o destino dos índices de liquidez é o destino dos mitos: são aceitos sem discussão porque são populares.

Entretanto, o conceito de liquidez é algo a ser revisto pelo mundo acadêmico e pela profissão contábil. A classificação circulante/não circulante deve ser abandonada e substituída por uma classificação de maior conteúdo informacional. Nem mesmo diante da hipótese de liquidação da empresa essa classificação resiste às críticas. Afinal, nessa hipótese, todos os ativos (e não apenas os circulantes) serão liquidados para o pagamento de todas as obrigações (e não apenas as circu- lantes). Se a hipótese de liquidação for afastada, a classificação circulante/não circulante também é inócua. Com efeito, como nos diz Loyd C. Heath em sua resposta às críticas ao seu artigo, "o argumento que o capital circulante líquido e o indice de liquidez corrente medem o grau de cobertura do passivo circulante pelo ativo circulante está baseado na suposta mas inexistente relação entre fontes e usos de caixa. Uma empresa gera caixa pela utilização conjunta de todos os seus ativos e não somente de seus ativos circulantes. É tão sem sentido se perguntar se o caixa da empresa vem do uso de seus ativos circulantes ou não circulantes como se perguntar se a produção de uma pessoa provém de seu coração, ou de seu fígado, ou de seu pulmão"(14).

Análise econômico-financeira não pode estar cercada por classificações ambíguas e por índices cujas fórmulas são, no mínimo, discutiveis. É preciso enxergar além dos números para se ter um diagnóstico mais preciso. É preciso que nos libertemos dos mitos. $\left.{ }^{(15)}\right]$

ABSTRACT: The traditional financial analysis supposes that the company will be closed in a short period of time and, arbitrarilly, classifies the so called liquidity ratios in pre-established standards.

Though these ratios are easy to be calculated it is mandatory that the users be aware of the Static condition of the information and that the liabilities will be paid by the funds produced by using the various assets and not by its liquidation.

The financial ratios has been overvalued as an efficient tool for bankruptcy forecast but lately the cash flow has been considered as a better tool in forecasting the financial problems of companies.

KEY TERMS: Debt ratio, going concern hypothesis, current asset, current liability, net working capital, cash flow.

10. HEATH, Loyd C. Op. cit., p.58 (nota de rodapé no. 17).

11. Idem, ibidem,p. 61.

12. Idem, ibidem.

13. PROFESSIONAL Notes and Letters. In: Journal of Accountancy, dezembro de 1981, pp. 82, 84, 86, 88, 90, 92 e 94.

14. HEATH,Loyd C. Resposta às críticas ao seu artigo - "Is Working Capital Really Working?" - in: Journal of Accountancy, dezembro de 1981, p. 94.

15. Este texto faz parte do convênio PRICE/FGV de estímulo à criação acadêmica. 